\title{
Application of a cooling tower model for optimizing energy use
}

\author{
G. C. O'Mary \& D. F. Dyer \\ Department of Mechanical Engineering, Auburn University, USA
}

\begin{abstract}
The overall objective of this paper is to develop and demonstrate a cooling tower model that allows any user to optimize energy use in the operation of an induced draft cooling tower. The objective is achieved by application of a theoretical model for the performance of a cooling tower. The model allows the determination of the exit cooling tower water temperature given the environmental conditions and tower design data and predicts fan energy use for both two-speed and variable speed fans. For validation, the model was applied to a cooling tower located at Russell Medical Center (RMC) in Alexander City, Alabama USA. The model results are compared with actual data from this tower and show excellent correlation. The verified model is then used to study two potential energy savings measures in the operation of a cooling tower as follows: (1) The actual potential savings at RMC through upgrading from a two-speed fan to a variable speed fan, and (2) Determining the optimum fan speed for the RMC cooling tower using a variable speed fan for a practical range of environmental conditions. Two overall conclusions are presented. First, a practical model that any user can apply in determining optimum operating conditions and potential energy savings for cooling towers is presented and verified. Second, the results applied to the specific cooling tower and HVAC system at RMC show significant savings in going from a two-speed fan to a variable speed fan, and optimum fan speed for minimum total energy consumption is not the maximum fan speed for most situations. Thus, it is demonstrated that the model presented is an excellent tool to allow operators to run an HVAC system efficiently and can serve as the basis for a control system that automatically operates the HVAC system at optimum conditions under various environmental conditions.

Keywords: cooling towers, energy conservation, HVAC, heat and mass transfer.
\end{abstract}




\section{Introduction}

Cooling towers are widely used in heating, ventilating, and air conditioning systems (HVAC) and in power generating plants based on the Rankine cycle. There are potential energy savings in the cooling tower itself as well as the refrigeration or power system to which it is connected. Simple modelling of the energy used in a cooling tower, employed in industrial and commercial boiler operations, can provide insight to owners and operators for reducing their operating costs. Figure 1 shows a schematic of a typical induced draft tower.

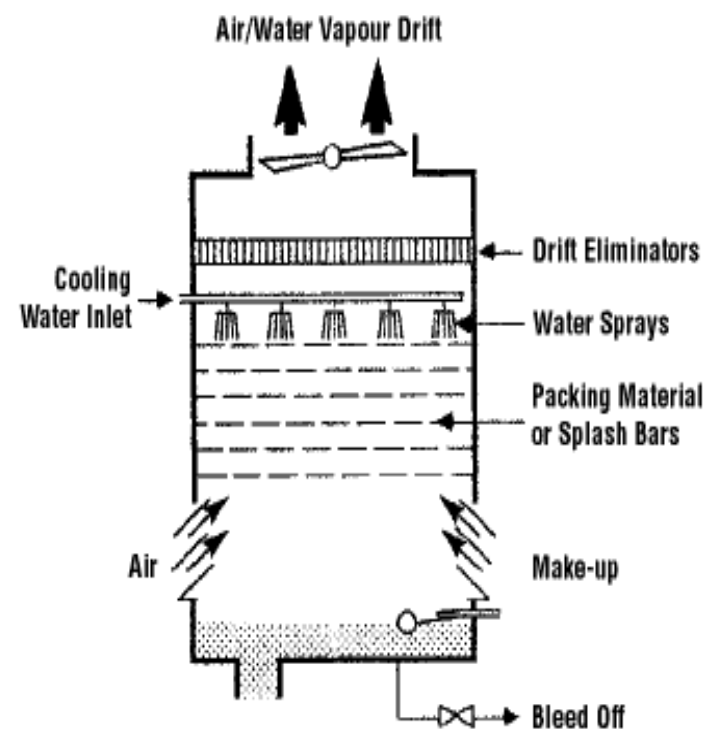

Figure 1: Cross section of cooling tower.

This paper presents and applies a model for the heat and mass transfer in a cooling tower used in HVAC. A cooling tower works by inducing evaporation by air flow across fill material that saturates the air and, at the same time, pulls energy from the water lowering its temperature. This cooled water is used to remove heat from the condensing section of refrigeration devices and from the condenser in power plants. There is always a trade-off between lowering the water temperature leaving the cooling tower by increasing air flow and fan power in order to achieve higher efficiency in the HVAC system or power plant.

This paper describes a model for cooling towers used in HVAC that allows optimization of the trade-off between fan power and HVAC system efficiency. First, the model development is described followed by a comparison of model results to actual field results to validate the model. The model is then applied as an example to show the energy savings for two situations: 1. upgrading fan control, and 2. operating the fan at optimum speed. Finally, conclusions are drawn from the application of the model presented earlier. 


\section{Model developments}

Consider a schematic of the cooling tower being studied in this paper shown in Figure 1. Based on a heat and mass transfer model of the tower by Braun [1] and O'Mary [2], one can arrive at the following equations. First the airside effectiveness defined as the ratio of the actual heat transfer to the maximum possible heat transfer is given by equation (1).

$$
\dot{\varepsilon}_{a}=\frac{1-e^{-N T U\left(1-m^{*}\right)}}{1-m^{*} e^{-N T U\left(1-m^{*}\right)}}
$$

where NTU is the heat exchanger number of transfer units and $m^{*}$ is a dimensionless variable defined by.

$$
m^{*}=\frac{\dot{m}_{a}}{\dot{m}_{w}\left(\frac{C_{p w}}{C_{s}}\right)}
$$

$C_{s}$ is estimated as the average slope between the inlet and outlet water conditions, i.e.

$$
C_{s}=\frac{h_{s, w, i}-h_{s, w, o}}{T_{w, i}-T_{w, o}}
$$

where $h_{s, w, o}$ is the enthalpy of the exiting water;

$h_{s, w, i} \quad$ is the enthalpy of the entering water;

$T_{w, i} \quad$ is the temperature of the entering water;

$T_{w, o} \quad$ is the temperature of exiting water.

The outlet air enthalpy and water temperature can then be calculated using the following equations:

$$
\begin{gathered}
h_{a, o}=h_{a, i}+\varepsilon_{a}\left(h_{s, w, i}-h_{a, i}\right) \\
T_{w, o}=\frac{\left(T_{w, i}\right)-\dot{m}_{a}\left(h_{a, o}-h_{a, i}\right)}{\dot{m}_{w} c_{p w}}
\end{gathered}
$$

Equations (1) through (5) are based on realistic assumptions that include:

- Heat and mass transfer in the normal direction to flow;

- Heat and mass transfer through tower walls neglected;

- Heat transfer from the tower fans neglected;

- Constant water and dry air specific heats;

- The mass fraction of water vapour in the air/vapour mixture approximately equal to the humidity ratio;

- Uniform temperature throughout the water stream at any cross sectional area of the tower;

- Constant cross sectional area for the tower;

- Lewis Number equal to unity for air in tower.

In order to use Equations (1) through (5) for analysing a given cooling tower, one must input the tower design conditions. Table 1 lists the design conditions for the RMC cooling tower studied in this paper. 
Table 1: Design criteria for the RMC cooling tower.

\begin{tabular}{|c|c|}
\hline Parameter & Value \\
\hline Inlet air dry bulb temperature, $\mathrm{C}$ & 35 \\
\hline Exit air dry bulb temperature, $\mathrm{C}$ & 29.4 \\
\hline Inlet air wet bulb temperature, $\mathrm{C}$ & 25.5 \\
\hline Design water flow rate, cubic meters/hr & 450 \\
\hline Design air flow rate, cubic meters/min & 5,082 \\
\hline $\begin{array}{c}\text { Inlet water temperature minus outlet } \\
\text { water temperature, C }\end{array}$ & 5.5 \\
\hline $\begin{array}{c}\text { Outlet water temperature minus wet bulb } \\
\text { temperature, C }\end{array}$ & 3.9 \\
\hline
\end{tabular}

The model accepts outdoor air temperature, relative humidity, and wet bulb temperature as inputs. From those inputs, entering water and air enthalpy are calculated using equations defined from curve fits of air and water enthalpy at different weather conditions. Tower NTU must be determined in order to correctly predict outlet water temperatures. NTU [3] is a dimensionless constant that defines the heat transfer capability of the tower relative to its size. It remains constant with a constant air and water flow rate. If air flow rate or water flow rate change, the NTU value changes. RMC's cooling tower is equipped with two speed fans. It has two possible air flow rates and one possible water flow rate. Based on these facts, three separate NTU values for maximum air flow, for half speed air flow, and for natural convective air flow are found. Calculating NTU requires an iterative process. Equations (1)-(5) are iterated in order to find the appropriate value for NTU. Known design input conditions are used in this process so that the only unknown is the value of NTU. This process is automated in MATLAB. The correct NTU value for the RMC cooling tower at design conditions is found to be 6.72. This value decreases with the smaller air flow rates. Half flow produces an NTU value of 4, and the fan off NTU is 0.8 .

After determining the value of NTU for the RMC cooling tower, the first objective is to demonstrate that the model gives valid results for offdesign conditions. This requires obtaining the outlet water temperature at off-design conditions over the course of a day. The outlet water temperature for off-design conditions can be determined directly with the model. Known weather conditions can be used in a step by step process where operating conditions are calculated in small time increments (say 30 minutes) using equations (1) to (5). After each time step new weather conditions and chiller load are used as input in making these calculations. The chiller load allows the enthalpy change of water across the tower to be determined which, in turn, allows determination of the inlet water enthalpy since the exit water enthalpy is known from the previous step. The NTU value corresponding to the fan speed is being used as input. The fan speed is determined from the control algorithm used at RMC. To calculate fan power in this process, the fan curve from the manufacturer is used. The output of interest in this calculation is the cooling 
tower exit water temperature. This calculation compared to actual data will give an accurate assessment of the validity of the model.

Another objective of this paper is to determine the amount of energy savings through the use of a variable speed fan as compared to a 2-speed fan on a month by month basis. The procedure described directly above can also be used to calculate the fan power required during each month of the year. The only modification to the technique described above is that the NTU for variable speed is curved fitted based on the data obtained as described above for high speed, low speed, and fan off conditions. The output results of the model for this situation are the power consumed by the cooling tower fan.

A final objective of this paper is to show that the optimum fan speed in variable speed operation can lie somewhere between minimum and maximum fan speed. In order to determine the fan power and chiller compressor power that provides the minimum total power, the model described above is used. Known weather conditions and chiller load are used as input to equations (1) to (5). In addition the exit water temperature is specified. The required air flow rate to satisfy these equations is obtained by iteration of these five equations. The iteration process is similar to that employed to find the NTU value as described above with the exception that the value of $\mathrm{m}^{*}$ is guessed instead of NTU. Once $\mathrm{m}^{*}$ is known the air flow rate can be calculated from equation (2) and then the required fan speed and power is determined from the fan curve. The chiller power is determined based on its coefficient of performance with the known inlet condenser water temperature (water temperature leaving the cooling tower). The output of this calculation is fan cooling tower power, chiller power, and total of fan power and chiller power.

The actual Mat Lab code for the models described in the model development section is listed in the thesis by O'Mary [2].

\section{Results}

This section gives results for each of the three objectives described in model development section. The first objective is to demonstrate that the model results for outlet water temperature are very close to predicting actual results. This demonstration is carried out by computing results for outlet water temperature for various weather conditions and chiller loading at RMC and comparing to actual measured data. The result of this study is shown in Figure 2. The data show that the sum of the squares of the distances of the data points from the bestfit linear curve $\left(\mathrm{R}^{2}\right)$ is 0.985 indicating that the model produces nearly perfect predictions of actual data. 


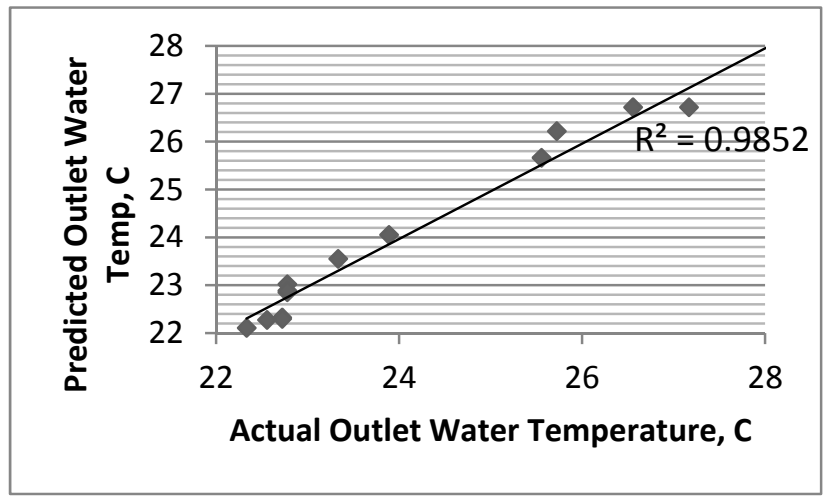

Figure 2: Validation data for model.

The actual data used to generate Figure 2 is shown in Table 2 also indicating the validity of the model used.

The second objective is to determine the potential fan power savings by converting from a two-speed fan to a variable speed drive. To meet this objective the model described above is used to analyse the month-by-month savings due to upgrading from two-speed fan operation to variable speed operation at the RMC facility. The results are shown in Table 3.

Table 2: Actual vs. predicted outlet water temperature.

\begin{tabular}{|c|c|}
\hline $\begin{array}{c}\text { Actual Data, } \\
\text { C }\end{array}$ & $\begin{array}{c}\text { Predicted Data, } \\
\text { C }\end{array}$ \\
\hline 22.72 & 22.33 \\
\hline 22.72 & 22.30 \\
\hline 22.78 & 22.86 \\
\hline 22.78 & 23.02 \\
\hline 22.78 & 22.89 \\
\hline 22.56 & 22.28 \\
\hline 22.33 & 22.11 \\
\hline 23.33 & 23.56 \\
\hline 23.89 & 24.06 \\
\hline 25.56 & 25.67 \\
\hline 27.17 & 26.72 \\
\hline 26.56 & 26.72 \\
\hline 25.72 & 26.22 \\
\hline 29.44 & 29.39 \\
\hline 28.56 & 28.22 \\
\hline
\end{tabular}


Table 3: Fan power savings.

\begin{tabular}{|l|c|c|c|}
\hline Month & $\begin{array}{c}\text { 2-speed fan } \\
\text { energy usage } \\
\text { (kwh) }\end{array}$ & $\begin{array}{c}\text { VFD fan } \\
\text { energy usage } \\
\text { (kwh) }\end{array}$ & $\begin{array}{c}\text { Monthly } \\
\text { savings } \\
\text { (kwh) }\end{array}$ \\
\hline Jan & 1980 & 1650 & 330 \\
\hline Feb & 1830 & 1480 & 350 \\
\hline Mar & 2750 & 2450 & 300 \\
\hline Apr & 3389 & 2976 & 413 \\
\hline Jan & 6417 & 5758 & 659 \\
\hline Jun & 10554 & 9864 & 690 \\
\hline Jul & 9662 & 8544 & 1118 \\
\hline Aug & 10713 & 9486 & 1227 \\
\hline Sep & 8523 & 7418 & 1105 \\
\hline Oct & 4323 & 3855 & 468 \\
\hline Nov & 2169 & 1835 & 334 \\
\hline Dec & 1734 & 1392 & 342 \\
\hline Total: & 64044 & 56708 & 7336 \\
\hline
\end{tabular}

It should be noted that the savings listed above do not include savings due to improved chiller performance. The savings total is enough to garner better than a two year pay back on the conversion from two-speed to variable speed fan control.

A final objective for this work is to show that the optimum fan speed is not necessarily the maximum or minimum speed. The authors have considerable experience in studying numerous cooling tower operations across the United States. Almost invariably, facility operations personnel do not take advantage of optimizing fan speed in order to minimize the total power input to the cooling tower fan and chiller compressor. The result of this calculation is shown in Figure 3 based on a $15.6^{\circ} \mathrm{C}$ wet bulb temperature

Figure 3 shows that the minimum total power occurs at an exit water temperature of about $20.5^{\circ} \mathrm{C}$. By running the fan at max speed, an exit water temperature of $19.5^{\circ} \mathrm{C}$ could be achieved. Hence, the optimum fan speed is somewhat less than the maximum. At different wet bulb temperatures, the optimum fan speed changes. However, this data show that the control sequence of operation of a cooling tower should not set the desired outlet water temperature at a fixed value; rather it should be set to achieve minimum power for the system. 


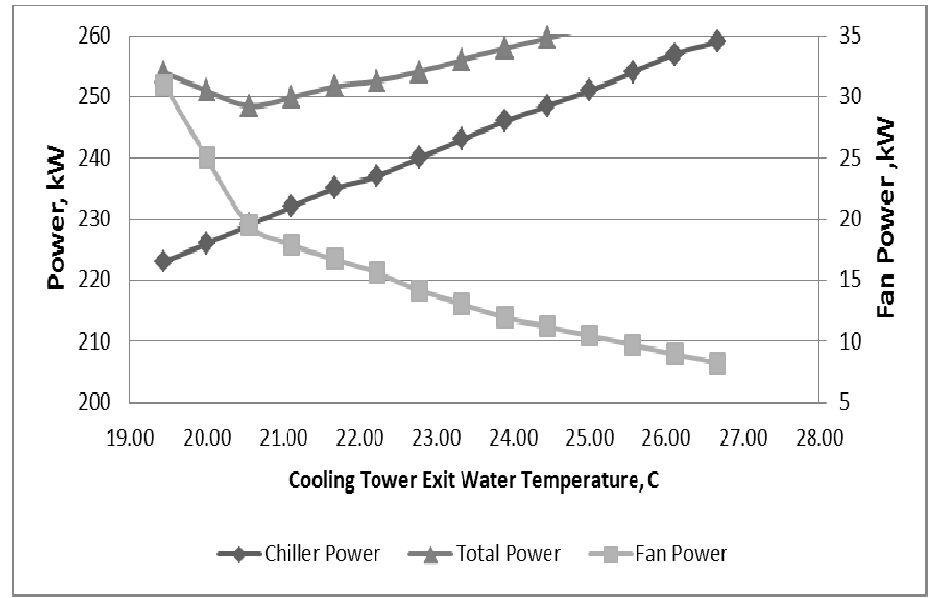

Figure 3: Optimum fan speed for minimum total power.

\section{References}

[1] Braun, J.E., Methodologies for the Design and Control of Cooling Towers, (Madison Wisconsin: PhD Thesis, University of Wisconsin 1988).

[2] O’Mary, G.C., Energy Cost Reduction for Medical Facilities: (Auburn, Alabama: Master's Thesis, Auburn University, 2012).

[3] Incropera, F.P., DeWitt, D.P., Bergman, T.L., Lavine, A.S., Fundamentals of Heat and Mass Transfer sixth Edition pp. 686-705, (New York, John Wiley and Sons, 2007). 